\title{
Reply to Zhang and Zhu "MicroRNA Mimics or Inhibitors as Antiviral Therapeutic Approaches Against COVID-19"
}

\author{
Nadine Ahmed ${ }^{1} \cdot$ John Paul Pezacki ${ }^{1}$ (D) \\ Accepted: 26 July 2021 / Published online: 28 August 2021 \\ (C) The Author(s), under exclusive licence to Springer Nature Switzerland AG 2021
}

\section{Dear Editor,}

We are writing in response to the accompanying letter from Zhang and Zhu [1]. We have read their response and understand their perspective; however, we nevertheless maintain an optimistic view of the possibilities of microRNA (miRNA)-based therapeutics. In our original article, we examined the possibilities of SARS-CoV-2 interacting with different miRNAs with a forward-looking perspective on their therapeutic potential [2]. There are many examples of RNA viruses, including coronaviruses, interacting with the RNA-silencing pathway through direct or indirect interactions [3-5].

Firstly, it is important to note that miRNAs have been shown in multiple instances to be predictive biomarkers for human infection, suggesting that perturbations of miRNA expression and function are maintained in the clinical disease [6-9]. These perturbations can act as indications for the presence of a pathology or highlight a link to pathogenesis. Thus, identifying profiles of miRNAs that are dysregulated during diseased states may aid in preclinical efforts or even diagnosis of viral infections and other diseases as well as inform on therapeutic potential. Therefore, one of our main points in our original article is that these interactions are likely to be occurring during SARS-CoV-2, as has been found with other RNA viruses [2]. In cases where miRNAs are being utilized by the virus as host factors that assist the virus life cycle, blocking these interactions will restrict the virus in a drug-like manner [2]. Furthermore, if the dysregulation in miRNA expression is linked to severity of disease, modulating these effects may be lifesaving. Therefore, there

This reply refers to the article available at https://doi.org/10.1007/ s40265-021-01474-5.

John Paul Pezacki

John.Pezacki@uottawa.ca

1 Department of Chemistry and Biomolecular Sciences, University of Ottawa, Ottawa, ON K1N 6N5, Canada is justification and a need to further understand these interactions and to maintain hope for successful targeting of these virus-induced changes therapeutically. There are many direct and indirect methods for miRNA targeting-including the delivery of chemically modified miRNA mimics and inhibitors, small molecular inhibitors of specific miRNAs, antimiRNA oligonucleotides and molecular sponges [10-14].

While it is true that miRNA therapeutics have not yet reached the clinic, we feel that this field is still in its infancy compared with more traditional approaches to drug development. Our collective understanding of miRNA signaling continues to grow and evolve, and with new understanding comes new opportunities. Furthermore, pharmaceutical industries need time to overcome the technical hurdles for implementation of such therapies. The fact that siRNA therapeutics are now reaching the clinic is cause for hope and optimism [15]. Despite siRNA technology being quite well understood and implemented in pre-clinical studies, it took more than 10 years to translate that understanding into clinical solutions [15]. Because miRNAs have evolved to be endogenous signaling molecules that regulate gene expression, and can target multiple components within the same pathway or even multiple related pathways, they can have a more pronounced phenotypic effect [16]. In addition, they fine-tune endogenous gene expression by regulating feedforward and negative-feedback loop mechanisms, where the mRNA and the miRNA are being modulated, and that allows for endogenous regulation of protein expression levels [16]. This makes their roles more complicated than a simple siRNA that may target only one mRNA selectively. However, miRNAs as also subject to evolutionary pressure and have evolved functions. Thus, mimicking or inhibiting that function, we argue, does have therapeutic potential.

We agree that there are more challenges to developing therapeutics that target or mimic miRNAs; however, this does not mean we should not try to do so. One can argue that the most effective drugs currently used in the clinic do in fact target several components within the same cellular 
signal transduction pathway. Thus, the selectivity profile of some small-molecule drugs make them more desirable due to their efficiency, potency and effectiveness [17]. Many of these pharmacologically designed small-molecule drugs act to modulate several protein targets rather than a single target to give rise to a more pronounced phenotype. Since miRNAs have evolved to target multiple proteins within a given pathway, this provides support for miRNA-based therapeutics [17]. Another example that highlights the potential of miRNA-based therapeutics in infectious disease is inhibiting miR-122-hepatitis C virus (HCV) interactions. Miravirsen and RG-101 are anti-miR122 oligonucleotides that have been found, through phase 1 and phase 2 clinical trials, to decrease HCV RNA levels in chronic HCV patients. These clinical trials should provide hope for targeting miRNAmediated virus-host interactions [18, 19]. However, each miRNA will have its own unique set of challenges. While Zhang and Zhu are correct in stating that miRNA-based therapeutics are immature and difficult to administer, these are technical challenges that can be overcome through innovation [1].

In our original article we considered the therapeutic potential of miRNAs in the context of blocking virus propagation generally, and we did not discuss how these targets might translate into clinical solutions [2]. Discovering that miRNA can be pro- or antiviral through the use of antagonists or mimics is the initial step in the pre-clinical journey. The ability to directly target a given miRNA depends on its evolved function. Where miRNAs function as cellular signal transducers, the delivery of miRNA mimics or inhibitors may offset the effects of the virus without having major offtarget effects. If done correctly, this would simply reverse the virus-induced effects and lead to an antiviral state in the infected cell. Other technical challenges include delivery to the site of infection and dosing to maintain an ideal mRNAmiRNA ratio [20, 21]. Furthermore, as pointed out in our original article, indirect approaches can be used where small molecules are utilized to inhibit the miRNA or its targets $[10,14,22]$.

In our original manuscript we really focused on preclinical studies to identify host factors that may restrict or enhance SARS-CoV-2 replication. We concede the point that therapeutics based on miRNAs will not be an easy path and we recognize that there are many challenges to getting drugs of this class into the clinic. However, similar targets that regulate signal transduction are now being routinely targeted by small molecules, biologics and even siRNAs [15]. The technical hurdles in these other instances have been overcome by innovations in both academia and industry. Thus, there is hope that the technical hurdles will also be overcome for the targeting of miRNAs. We have considered the case where miRNAs are being modulated by the virus to create a pro-viral state in infected lung tissue. If miRNA signaling is being modulated directly by viral infection, then targeting the miRNA with mimics or inhibitors ideally restores the normal cellular condition and an antiviral state may then be established. The argument around off-target effects is important to consider; however, if a virus like SARS-CoV-2 is dysregulating an miRNA to a significant extent, it will dysregulate all the targets of the miRNA. Simply reversing this should not be a major cause for concern so long as the therapy it delivered specifically to the site of infection and dosed correctly. Furthermore, miRNAs can be used in combination with other therapeutics. For these reasons, we maintain our optimistic view of the potential for miRNAbased therapeutics.

Finally, we can draw analogies to the influenza pandemic of 1918. That pandemic involved an H1N1 influenza strain that still plagues the world today, re-emerging from time to time (most recently in 2009). Both vaccination and clinical treatments are useful in saving lives for this virus [23, 24]. It may turn out to be the case for SARS-CoV-2 that this strain also continues to reappear. If this is the case, then reemerging societal challenges will parallel the instances of re-emergence. Thus, longer-term efforts to combat the virus through different means will be valuable to save lives, especially for variants that may emerge in the future. We maintain an optimistic view that miRNAs can be drug targets and therapies around miRNAs, although technically challenging, still hold promise.

Acknowledgements N.A. is supported by an NSERC Postgraduate Scholarship-Doctoral (PGSD). This work is supported by funding from a Natural Sciences and Engineering Research Council (NSERC) grant (298496) and a Canadian Institutes of Health Research (CIHR) grant (136807). We also thank the other authors of our original manuscript, C. Hum, J. Loiselle, T. A. Shaw and C. Toudic, for their helpful discussions.

\section{Declarations}

Conflict of interest The authors declare no competing interests.

Ethics approval Not applicable.

Consent for publication Not applicable.

Availability of data and materials Not applicable

Author contributions JPP and NA conceived of the idea; JPP and NA developed the first draft; all authors approved the final manuscript.

\section{References}

1. Zhang S, Zhu F. Comment on: "MicroRNA mimics or inhibitors as antiviral therapeutic approaches against COVID-19". Drugs. 2021. https://doi.org/10.1007/s40265-021-01582-2. 
2. Hum C, Loiselle J, Ahmed N, Shaw TA, Toudic C, Pezacki JP. MicroRNA mimics or inhibitors as antiviral therapeutic approaches against COVID-19. Drugs. 2021;81:517-31. https:// doi.org/10.1007/s40265-021-01474-5.

3. Cui L, Wang H, Ji Y, Yang J, Xu S, Huang X, et al. The nucleocapsid protein of coronaviruses acts as a viral suppressor of RNA silencing in mammalian cells. J Virol. 2015;89:9029-43.

4. Fabozzi G, Nabel CS, Dolan MA, Sullivan NJ. Ebolavirus proteins suppress the effects of small interfering RNA by direct interaction with the mammalian RNA interference pathway. J Virol. 2011;85:2512-23.

5. Chen W, Zhang Z, Chen J, Zhang J, Zhang J, Wu Y, et al. HCV core protein interacts with Dicer to antagonize RNA silencing. Virus Res. 2008;133:250-8.

6. Lanford RE, Hildebrandt-Eriksen ES, Petri A, Persson R, Lindow M, Munk ME, et al. Therapeutic silencing of microRNA-122 in primates with chronic hepatitis $\mathrm{C}$ virus infection. Science (80-). 2010;327:198-201.

7. Hu WZ, Tan CL, He YJ, Zhang GQ, Xu Y, Tang JH. Functional miRNAs in breast cancer drug resistance. Onco Targets Ther. 2018;11:1529-41.

8. Li YJ, Xu M, Gao ZH, Wang YQ, Yue Z, Zhang YX, et al. Alterations of serum levels of BDNF-related miRNAs in patients with depression. PLoS ONE. 2013;8:1-7.

9. Tambyah PA, Ching CS, Sepramaniam S, Ali JM, Armugam A, Jeyaseelan K. microRNA expression in blood of dengue patients. Ann Clin Biochem. 2015;53:466-76.

10. Costales MG, Aikawa H, Li Y, Childs-Disney JL, Abegg D, Hoch DG, et al. Small-molecule targeted recruitment of a nuclease to cleave an oncogenic RNA in a mouse model of metastatic cancer. Proc Natl Acad Sci USA. 2020;117:2406-11.

11. Bose D, Jayaraj G, Suryawanshi H, Agarwala P, Pore SK, Banerjee $\mathrm{R}$, et al. The tuberculosis drug streptomycin as a potential cancer therapeutic: inhibition of mir-21 function by directly targeting its precursor. Angew Chemie Int Ed. 2012;51:1019-23.

12. de Melo MB, Ling H, Monroig P, Ciccone M, Soares FA, Calin GA, et al. Design of a miRNA sponge for the miR-17 miRNA family as a therapeutic strategy against vulvar carcinoma. Mol Cell Probes. 2015;29:420-6. https://doi.org/10.1016/j.mcp.2015. 08.002 .

13. Lima JF, Cerqueira L, Figueiredo C, Oliveira C, Azevedo NF. Anti-miRNA oligonucleotides: a comprehensive guide for design. RNA Biol. 2018;15:338-52.
14. Suresh BM, Li W, Zhang P, Wang KW, Yildirim I, Parker CG, et al. A general fragment-based approach to identify and optimize bioactive ligands targeting RNA. Proc Natl Acad Sci USA. 2021;117:33197-203.

15. Zhang MM, Bahal R, Rasmussen TP, Manautou JE, Zhong X. The growth of siRNA-based therapeutics: Updated clinical studies. Biochem Pharmacol. 2021;189:114432.

16. Ebert MS, Sharp PA. Roles for MicroRNAs in conferring robustness to biological processes. Cell. 2012;149:515-24. https://doi. org/10.1016/j.cell.2012.04.005.

17. Hopkins AL. Network pharmacology: The next paradigm in drug discovery. Nat Chem Biol. 2008;4:682-90.

18. Van Der Ree MH, Van Der Meer AJ, Van Nuenen AC, De Bruijne J, Ottosen S, Janssen HL, et al. Miravirsen dosing in chronic hepatitis $\mathrm{C}$ patients results in decreased microRNA-122 levels without affecting other microRNAs in plasma. Aliment Pharmacol Ther. 2016;43:102-13.

19. van der Ree MH, de Vree JM, Stelma F, Willemse S, van der Valk M, Rietdijk S, et al. Safety, tolerability, and antiviral effect of RG-101 in patients with chronic hepatitis C: a phase 1B, doubleblind, randomised controlled trial. Lancet. 2017;389:709-17. https://doi.org/10.1016/S0140-6736(16)31715-9.

20. Dasgupta I, Chatterjee A. Recent advances in miRNA delivery systems. Methods Protoc. 2021;4:1-18.

21. Baumann V, Winkler J. MiRNA-based therapies: strategies and delivery platforms for oligonucleotide and non-oligonucleotide agents. Future Med Chem. 2014;6:1967-84.

22. Filip R, Desrochers GF, Lefebvre DM, Reed A, Singaravelu R, Cravatt BF, et al. Profiling of microRNA targets using activitybased protein profiling: linking enzyme activity to microRNA-185 function. Cell Chem Biol. 2021;28:202-212.e6.

23. Lansbury LE, Smith S, Beyer W, Karamehic E, Pasic-Juhas E, Sikira $\mathrm{H}$, et al. Effectiveness of 2009 pandemic influenza A (H1N1) vaccines: a systematic review and meta-analysis. Vaccine. 2017;35:1996-2006. https://doi.org/10.1016/j.vaccine.2017.02. 059.

24. Rewar S, Mirdha D, Rewar P. Treatment and prevention of pandemic H1N1 influenza. Ann Glob Health. 2015;81:645-53. 